\title{
Application of Watson Caring Theory for Nurses in Pediatric Critical Care Unit
}

\author{
Hanan T.,Elbahnasawy ${ }^{*}$, JosephinLawend $^{* *}$, EntsarKamel Mohammed ${ }^{* * *}$ \\ *Assistant Professor, Pediatric Nursing, El-Menofya University-Egypt \\ ** Lecturer, Pediatric Nursing, El-Mansoura University-Egypt \\ ***Lecturer, Medical Surgical Nursing, El-Menofya University-Egypt \\ Currently in Jazan University
}

\begin{abstract}
Caring is considered as the essence of nursing and is the basic factor that distinguishes between nurses and other health professions. The literature is rich of previous studies that focused on perceptions of nurses toward nurse caring behaviors, but less studywas applied in pediatric nurses in different settings.

Aim of the study:evaluate the effect of application of Watson caring theory for nurses in pediatric critical care unit. Method(s): A convenience sample of 70 nurses of Pediatric Critical Care Unit in El-Menoufya University Hospital and educational hospital in ShebenElkom.were completed the demographics questionnaire, and the Caring Behavior Assessment (CBA) questionnaire,medical record to collect medical data regarding children characteristics such as age and diagnosis, Interviewing questionnaire for nurses regarding their barrier to less interest of comfort behavior such as doing doctor order, Shortage of nursing staff, Large number of patients, Heavy workloads, Secretarial jobs for nurses and Emotional stress.

Results: more thantwothirds of nurses in study group and majority of control group had age less than 30 years, there were highly statistically significant difference related to mean scores for Caring Behavior Assessment (CBA) as rated by nurses in pretest (1.4750 to 2.0750) than in posttest (3.5 to 4.55). Also, near to two-thirds (64.3\%) of the nurses stated that doing doctor order act as a barrier to apply this theory. In addition, there were a statistical significance difference between educational qualifications of nurses and a Supportivel protectivelcorrective environment subscale with mean score for master degree 57.0000, also between years of experiences and human needs assistance.

Conclusion: Program instructions for all nurses to apply Watson Caring theory for children in pediatric critical care unit were successful and effective and this study provided evidence for application of this theory for different departments in all settings.

Recommendations: It was recommended that In-service training programs for nurses about caring behavior and its different areas, with special emphasis on communication are needed to improve their own behaviors in all aspects of the caring behaviors for all health care settings. Motivating hospital authorities to recruit more nurses, then, the nurses would be able to have more care that is direct. Consequently, the amount and the quality of nurse-child communication and opportunities for patient education would increase, this in turn improve child's outcome.
\end{abstract}

Keywords: Watson caring theory, pediatric critical care unit, Nurses, Caring behavior.

\section{Introduction}

Illness and hospitalization threatens children's sense of wellness welfare, security, independence, and self-control. Children's positive and negativeperceptions of their hospitalization experience are also influenced by their illness, invasive treatments, medications, and length of stay. Children have a limited understanding of the hospital environment and treatment as well as limited control over whatis happening to them. This makes them vulnerable when admitted to the hospital. (1)

Approximately 27\% of children in the worldwide have a chronic condition and 1 in 15 have multiple chronic conditions (MCCs) (2). Moreover, research indicates that the prevalence of chronic conditions is on the rise among pediatric patients $(3,4)$. Studies investigating health care use and cost in this population have been limited. Most research has been conducted on children with special health care needs, which are often considered to include MCCs. However, research into children with special health care needs has primarily focused on children with chronic illness, rather than broader pediatric populations with MCCs. (5)

Nursing theories are the basis of a body of knowledge that is structured and organized to support practice. Today, there is still a gap between theory and practice in nursing, which means theoretical models are rarely used and, because of that, theory-guided practice remains only an ideal for most institutions. Theoretical frameworks based on the science of care have brought improvements to: cost-effectiveness of patient care; communication and education; advancement of nursing research; and recognition and appreciation of the professionals. (6) 
Jean Watson's theory (1999) isa human science and human care theory involves many concepts that is difficult for children to understand at the level in which she presents them. Caring is an important concept in nursing. It has become the essence and central focus of nursing. Furthermore, it is a complex, elusive concept not only to define but also to measure and to provide for children through concrete behavior. To identify nurses' perceptions ofwhich nursing behaviors are important as caring behavior means to understand how caring is offered. It mightbe meaningful to show the concept of caring in terms ofconcrete behaviors. (7)

Nursing care for children should be tailored towards helping them make necessary adjustment needed for hospitalized care. This will help children to be able to cooperate better with nursing as well as medical activities enhancing quick recovery. A good understanding of what nurse caring behaviors are important to the hospitalized child will equip the nurse on how to meet these needs. Thus helping the sick child make necessary adjustment relative to his / her care as he/she goes through the hospital experience.(8)

Nursing is a helping profession with caring as its core and also, is categorized as a humanitarian science and characterized as a profession that performs personal, scientific, ethical, and aesthetical practice (8). According to Watson (2005), caring is a set of universal humanistic altruistic values. These values includekindness, empathy, concern, and love for selfand others. The values are derived fromchildhood experiences and are enhanced bybeliefs, cultures and arts. Altruistic values arisefrom commitments to and satisfaction fromreceiving through giving. Theybring meaning to one's life through one's belief and relationships with other people. Humanistic-altruistic feelings constitute thefirst and most basic factor for science and ethic of caring.(9)

Historically,caringhas been considered as the cornerstone for how and why nurses' practice, teaches, and advocate. The caring nurse is more than just a general broad layperson notion of giving, sharing, and attending to, respecting, honoring, and loving (10).Boev,stated that nurse caring is dependent upon the specific patient needs and the healthcare setting. Only once the specific patient needs and the healthcare setting are evaluated do nurses decide on an appropriate caring approach for the patient. Patients' perceptions of how they want to be cared for is reflected in many studies on quality of care.(11)

Watson's Human Caring theory focuses on human and nursing paradigm andaims to ensure a balance and harmony between health and illness experiences of children (12).It asserts that a human being cannot be healed asan object. It claims, on the contrary, that he/she ispart of his/her self, environment, nature, and thelarger universe. In this theory, the environment isdefined as comfortable, beautiful, and peacefulplace and that caring is the moral ideal that entails mind-body-emotion engagement with one another. $(13,14 \& 15)$

Caring behaviors are defined as; Behaviors evidenced by nurses in caring for patients. The top ten caring behaviors, derived from nursing literature are; attentive listening, comforting, honesty, patience, responsibility, providing information so the patient can make an informed decision, touch, sensitivity, respect, calling the patient by name.(16)

\section{Significance of the problem:}

In Egypt, there were 532 critically ill children admitted to the PICU over one year. Respiratory system diseases, foreign bodyinhalation removal, andencephalopathy werethe predominant etiologies of admission49.6, 11.9 , and $11.5 \%$, respectively.Mortalityrate was the highest in infants below 1 year ofage (43.9\%). Predominant length of ICU stay was around 7 days. (17)

Pediatric Intensive Care Unit (PICU) is different from other departments in hospitals in terms of the treatment methods and technical equipment used physicalappearance, and the nature of sensitiveenvironment. When the vital functions of patients decline in a risky way, they need to receivetreatment in an intensive care unit with a view to maintaining vital functions and applying special treatmentmethods (18).Patients in the intensive care unit experience

Changes in their comfort. Some reasons includeincrease in the anxiety level caused bychanges in consciousness level caused by painand use of sedatives; and movement restriction caused by the existence of invasive and noninvasivetools. (19)
Aim of the study
The aim of this study was to evaluate the effect of application of Watson caring theory for nurses in pediatric critical care unit through:
- Assessing the care of children needed in pediatric critical care unit to detect nurse's needs.
- Planning and Implementing caring theory application according to nurses' needs and
- Evaluating the effect of the theory on the caring of the children in critical care unit.

\section{Subjects and Methods}

Research design: Quasi experimental deign was conducted for this study. Technical Design: 
Setting: Pediatric Intensive Care Unit (PICU) in El-Menoufya University Hospital and educational hospital in ShebenElkom.

Sample: A convenient sample used in this study, all nursesproviding care for children in the above-mentioned settings the total numbers 70 nurses. This numberdivided randomly into two groups (40 for study and 30 for control).

\section{Tools of data collection:}

First tool: A structured interviewing questionnaire developed by researchers. It covered the following parts for both groups study and control

- Part One: Socio-demographic characteristics of nurses such as age, qualifications, level of education and years of experience.

- $\quad$ Part Two: Caring Behavior Assessment (CBA) Scale"(Pre/Post format).

The Caring Behavior Assessment (CBA) scale, which was developed by Cronin and Harrison (20) in 1988 and validated to measure the nurses' perceptions toward children caring behaviors in PICU of selected settings of this study. (CBA) scale was used to measure nurses' perceptions of nurse caring behaviors, which has a good psychometric properties based on well-known Watson's transpersonal theory (21). This scale was translated to Arabic language. It consisted of 63 items based on Watson's ten carative factors. The items of this scale are clustered into seven subscales as the following:

I-Humanism/Faith-hope/Sensitivity: items from 1 to 16 . Such as, Treat the child as an individual, Try to see things from the child point of view, Know what the child doing, Reassure the child, Make the child feel someone is there if I need them, Encouragethe child to believe in himself, Point out positive things about the child and his condition, Praise the child efforts, Understand the child, Ask the child how he likes things done, Accept the child the way he is, Be sensitive to the child feelings and moods, Be kind and considerate, Know when the child "had enough" and act accordingly (for example, limiting visitors), Maintain a calm manner and Treat the child with respect

II-Helping/trust: items from17 to 27.Such as, Really listen to the child when he talks, Accept the child feelings without judging him, Come into the child room just to check on him, Talk to the child about his life outside hospital, Ask the child what he likes to be called, Introduce themselves to the child, Answer quickly when the child call for them, Give the child their full attention when with him, Visit the child if he moves to another hospital unit, Touch the child when he needs it for comfort and Do what they say they will do.

III-Expression of positive/negative feelings: items from 28 to 31.Such as, Encourage the child to talk about how he feels, Don't become upset when I'm angry, Help the child understand his feelings and Don't give up on the child when him difficult to get

IV-Teaching/learning: items from 32 to 39.Such as, Encourage the child to ask questions about his illness and treatment, Answer the child questions clearly, Teach the child about his illness, Ask the child questions to be sure he understand, Ask the child what he wants to know about his health/illness, Help the child set realistic goals for his health, Help the child plan ways to meet those goals and Help the child plan for his discharge from hospital.

V-Supportive/protective/corrective environment: items from 40 to 51 .Such as, Tell the child what to expect during the day, Understand when the child need to be alone, Offer things (position changes, blankets, back rub, lighting, etc.) to make him more comfortable, Leave the child room neat after working with him, Explain safety precautions to the child and his family, Give the child pain medication when he needs it, Encourage the child to do what he can for himself, Respect the child modesty as, keeping him covered, Check with the child before leaving the room to be sure he has everything he needs within reach, Consider the child spiritual needs, Are gentle with the child and Are cheerful.

VI-Human needs assistance: items from 52 to 60 . Such as, Help the child with his care until he is able to do it for himself, Know how to give shots, IVs etc, Know how to handle equipment (for example, monitors), Give the childtreatments and medications on time, Keep the child family informed of his progress, Let the child family visit as much as possible, Check the child condition very closely, Help the child feel like he has some control and Know when it's necessary to call the doctor.

VII-Existential/phenomological/spiritual forces: items from 61 to 63. Such as, Seem to know how the child feel, Help the child see that his pastexperiences are important and Helpthe child feel good about himself. 


\section{Scoring System:}

The nurses were asked to fill the CBA questionnaire by choosing the best number that describe the importance of caring behaviors from $1-5$ (where $1=$ the least important caring behavior, and $5=$ the most important caring behavior). The CBA scale was translated to Arabic language by an expert in English language, then another expert who is proficient in both Arabic and English languages back-translated it to English language. Moreover, a panel of experts who are interested in the research topic and hold a doctorate degree in nursing also examined the Arabic version of the instrument for the clarity of its content. Their input was taken into consideration for more refining of the items.

- Second tool: Medical record to collect medical data regarding children characteristics such as age and diagnosis.

- Third tool: Interviewing questionnaire for nurses regarding their barrier to less interest of comfort behavior such as Doingdoctor order, Shortage of nursing staff, Large number of patients, Heavy workloads, Secretarial jobs for nurses and Emotional stress.

\section{Pilot study:}

A pilot study was carried out on five nurses from the PICU in the selected hospitals. It was conducted to test clarity and simplicity of questions and to check the most common topics related to the study. Necessary modifications were done by exclusion of some items which is not clear to the participants. Nurses who shared in pilot study were excluded from main study sample.

\section{Ethical considerations:}

Permission to conduct the study obtained from the dean of the Faculty and administrators of hospitals manager. Personal communication was done with nurses to explain the purpose of the study and assure their best possible cooperation. The researcher emphasized to nurses that the study was voluntary and anonymous. They had the full rights to refuse to participate in the study or to withdraw at any time without giving any reason.

\section{Field of Work:}

- A written official letter was obtained from the Dean of the Faculty of Nursing, El-MenoufyaUniversityand delivered to the administrator of hospitals in order to obtain the approval for conducting of the research after explaining its purpose.

- Data collection started with a verbal agreement was taken from every participant in the study after clear and proper explanation of the study purpose and its importance for them.

- The previous mentioned setting was visited by the researchers two days/week (Sunday and Monday) from $9.00 \mathrm{am}$ to $1.00 \mathrm{pm}$. The tools took about 30-45 minutes. Data collection took about six months.

- The study was carried out through four phases: assessment, planning, implementation, and evaluation.

- These phases were carried out from beginning of November 2014 to the end of April 2015. Pre test started for both groups (study and control) nurses and one month apart then start the post test.

- The researchers taught each group of nurses in a classroom setting in nursing station from 60-90 minutes for two consecutive days for each group of nurses.

- It was difficult to include all nurses in one place at the same time. Thus, the nurses were delivered the program of not more than five nurses in pretest then two nurses in the session for posttest.

- Program construction it contained 4 phases:

\section{Phase I:Program assessment:}

The researchers reviewed the recent, current, national and international related literature in various aspects related to Watson caring theory. Once the pretest conducted and analyzed, all needs of the nurses was identified. The program is based theory was in a form in Arabic language to be easy understood for the nurses.

Phase II:ProgramPlanning:

Program objectives: At the end of the program all nurses will apply Watson Caring theory for children in pediatric critical care unit.

Program contents designed based on Watson's seven behaviorsfactorsafter extensive review of related literature as the following:

- Humanism/ Faith - hope / sensitivity

- Helping/trust.

- Expression of positive/negative feelings. 
- Teaching/learning.

- Supportive/protective/corrective environment.

- Human needs assistance.

- Existential/phenomological/spiritual forces.

Staff education started with a booklet the author assembled for containing core concepts of Jean Watson's Theory of Human Caring, what "Caritas" means, a description of the sevenCaritas Processes, and articles related to transforming space using color, music and design. The booklets were given to each group of the staff.

\section{Phase III:Program Implementation:}

The researcher beginning with implementation of pretest to identify and determine the weak points of the nurses toward their care of children in critical care unit. The nursing intervention implemented in the form of sessions of different durations according to the content and response of nurses. The total number of sessions (pre and post) was 36 sessions. The time allocated for achieving the supportive education nursing intervention was two months and half. The sessions started by an orientation to the program and its purpose. Each session started by a summary of the previous session and objectives of the new session, using a simple language.

\section{Phase IV:Evaluation Phase:}

This done by measuring the change in nurses 'perception (posttest) about caring and comfortable measures application and how to manage it by using the same pretest, in order to identify differences, similarities and areas of improvement and defects.

\section{Statistical Analysis}

Data were revised, coded, tabulated and analyzed using numbers and percentage distribution and carried out in a PC computer SPSS programversion20. The following statistical techniques were used: Percentage, Mean, Standard deviation paired t-test for comparison of paired two quantity.

\section{Results}

Table (1) shows that $65 \%$ of age of the study group was between 19 to 29 years compared to $86.7 \%$ of them for control group. IN addition, 32.5\% of study had experience less than 5 years, while $26.7 \%$ of control group had experience more than 10 years.

Figure (1) shows that $50 \%$ of study group has bachelor degree and $47.5 \%$ of them has diploma.

Figure (2) shows that $70 \%$ of control group has bachelor degree and $30 \%$ of them has diploma

Table (2) representsmore than half $(55 \%)$ of children has age less than 10 years. Also, more than one third $(37.5 \%)$ of them has pneumonias, while $7.5 \%$ of them has foreign body inhalation.

Table (3A) shows mean scores for completed list of CBA items regarding Humanism/ Faith - hope / sensitivity and Helping/trust as rated by nurses. This table includes analysis of the most and least important nurse caring behaviors as perceived by participant (study group) nurses. This mean score as rated by nurses in posttest were ranged from 3.5 to 4.55 compared to pretest from 1.475 to 2.075 with highly statistically significant difference.

Table (3B) shows mean scores for completed list of CBA itemsregardingExpression of positive/negative feelings-Teaching/learning -Supportive/protective/corrective environment as rated by nurses. This table includes analysis of the most and least important nurse caring behaviors as perceived by participant (study group) nurse.An example of most important caring behavior as Leave the child room neat after working with him has highest mean score in posttest 4.400 compared to 1.700 for study group with highly statistically significant difference.

Table (3C) shows mean scores for completed list of CBA items regardingHuman needs assistance Existential/ phenomological/ spiritual forces as rated by nurses. This table includes analysis of the most and least important nurse caring behaviors as perceived by participant (study group) nurses. An example of least important caring behavior as Let the child family visit as much as possible has least mean score in posttest 3.975 compared to 1.866 for study group with highly statistically significant difference.

Table (4) shows barriers of nursing staff. About $52.9 \%$ of nurses stated that heavy workload act as a barrier toward application of Watson theory. Furthermore, near to two-thirds $(64.3 \%)$ of the nurses stated that doing doctor order act as a barrier to apply this theory.

Table (5)clarifies that there is a statistical significance difference between demographic characteristics of nurses regarding (educational qualifications) and an Supportivelprotectivelcorrective environment with mean for Diploma, Bachelor and Master 52.3158+4.83106 , $48.8500+5.38297$ and 57.0000 respectively, but there no statistical significant difference between demographic characteristics of nurses and other items of subscales.

Table (6)clarifies that there is a statistical significance difference between demographic characteristics of nurses regarding (years of experiences) and human needs assistance with years of experience less than year with mean $35.25+4.031$ compared to $40.363+2.062$ for more than 10 years and no statistical significance difference regarding to other items of subscale. 


\section{Discussion}

Watson (2002) developed a theory on human caring relationships and human experiences of life. This theory suggests that caring is a different way of being human, present, attentive, conscious, and intentional. In this theory, nursing focused on helping patients achieve highest degree of harmony within seven most important caring behavior. (22)

Regardingtosocio-demographic characteristicsof thenurses in table thisstudyresultsshowedthattheageofnurses in study group for two thirdsofthem ranged between19-29years, half of them had Bachelor degree of nursing and one third had 1-5years of experience in pediatric critical care unit and that correlated withMizuno et al., who stated that nurses who hold a bachelor's, master's, or doctor degree perceived knowing the individual as more important than those who graduated only from nursing schools (23).In addition this also agree with study was done in king Saud University by Sulimanet al., who reported that the majority of nurses who participated their ages were 20-30, two thirds hold diploma degree in nursing and had 1-5 years of experience(24). Findings in the table (2) revealed that children ageswere more than half of them were less than 10 years old and more than one third of them has pneumonia so those children need more care and comfortable.

Concerning completed lists of CBA items As ranked by the pediatric critical care nurses participant according to scores in table ( $3 \mathrm{~A}$ ) the present study showed that The mean score for most important nurse caring behaviors in Humanism/Faith-Hope/ Sensitivity as "treat the child as an individual"were improved post intervention led to significant improvements in nurses response to the CBA in the study group.This is in agreement with $\mathbf{O}$ 'Connell and Landers who reported that the results of the critical care nurses response to the CBA demonstrated that subscale 1(humanism/faith-hope/sensitivity) had the highest median score with the caring behaviors:'knows what you are doing', 'treat the child with respect', 'treat the child as an individual' 'reassure the child, 'is kind and considerate', 'know when the child has had enough and act accordingly' and 'maintain a calm manner' from subscale 1 identified among the 10 most important caring behaviors by nurses in the current study. The importance of these affective processes of caring has previously been demonstrated by research which used the CARE-Qinstrument(25). In addition Watson, who stated that this subscale which include kindness, empathy, concern, and love for self and others provides the basis of human caring thereby promote the best professional care (12). Also, Aderetiet al., added that that children appreciated nurses who smiled and used kind words, provided age-appropriate diversion and light-hearted conversation, promoted positive well-being and a sense of security, interacted with them as an individual and provided comfort and support (8).

Furthermore, in the same table reflected that, Subscale (helping/trust) was improved after implementation of program. The caring behavior "come into child room just to check on him" and " do what they say they will do" scored the lowest overall median for the study groups while subscale "really listen to child when he talks" the second lowest overall median for the control group. This finding was accepted with Villanueva, who reported that the low ranking of these subscales by the study and control group in this study could suggest that interpersonal nurse patient relationships may not be considered very important in the critical care setting. There are many barriers to building relations with patients in critical care settings such as the level of the nurse's experience and the difficulty experienced when communicating with unresponsive patients (26).

Regarding completed lists of CBA items As ranked by the pediatric critical care nurses participant according to scores in table $(3 \mathrm{~B})$ the present study showed that the teaching/learning subscale has some behavior has most important caring behavior as "Leave the child room neat after working with him" while the least score as "Ask the child questions to be sure he understands "and "Help the child plan for his discharge from hospital "this behavior require effective communication between patient and nurse and this is in line with a study by Liu, et al., in which patients reported that they required adequate explanations and that these explanations helped them feel more secure and safe and less anxious. They also emphasized that nurses need to find positive meanings, possibilities, and hope in situations that may appear bleak. It is also clear that, through caring, nurses can help shape patients' illnesses as positive experiences in which patients experience respect, dignity, comfort, and the feeling that the caregiver is there for them (27).

Findings in the table $(3 \mathrm{C})$ revealed that the top CBA items as ranked by nurse participants for study group in posttest that were considered as the most important caring behaviors. Items from Human needs assistance and Existential/ Phenomenological/ Spiritual Forces subscales had most important caring behaviors as perceived by nurses. This was confirmed by Azizi-Fini et al., who stated that the highest mean scores for CBA in the present study were related to the subscale of "Humanism/Faith-hope/ Sensitivity and Teaching/Learning", Which was consistent with the findings of other studies. Perhaps it was due to the high importance of this area from the perspective of the nurses. It may also be influenced by the more sensible nature of care practice in this area (28). 
Concerning of table (4) barriers of nursing staff to less interest of comfort behavior revealed that more than half of nurses stated that heavy workload act as a barrier toward application of Watson theory. Furthermore, near to two thirds of the nurses stated that doing doctor order act as a barrier to apply this theory.The mean score for one of least important nurse caring behaviors reflects this finding indicates the patients respect and emotional needs may be neglected from nurses due to a shortage of nursing staff, large number of patients and heavy workloads, Egyptian nurses spend most of their time and energy to do the doctors' orders, writing the reports and doing some secretarial jobs. Such a condition would cause nurses fatigue, and nervousness and would prevent professional caring relationships with patients and their families.

The findings of the present study in table (5) revealed relation between level of education of nurses \& their perception toward caring subscales. There is no significant relation between the nurses with different educational level and their perception toward caring behavior except in Supportivel protectivel corrective environment. This finding is in accordance with Poirier \&Sossong, who found no statistically significant differences between cancer nurses' perceptions of caring behaviors and their level of education(29). While this is contradicted with Mizuno et al., whose results meant that Japanese nurses' perception of important caring behavior was affected greatly by educational background. Nurses who hold Bachelor's degree, master's, doctor's degree perceived knowing the individual as more important than those who graduated only from nursing schools (23).

Furthermore, the current study showed relation between years of experience of nurses \& their perception toward caring behavior subscales in table (6). This recent study showed no significant relation between their year of experience and their perception toward caring behavior of patients except in human needs assistance. This is in agreement with Youssef et al., who have no significant relationship between their level of experience and their perception for patients in medical surgical ward among hospitals in Taif city in Saudi Arabia (30)

\section{Conclusion}

This study provides evidence of the applicability of using this theory as a basis for educational program curricula for nursing students and a basis for the provision of nursing care in different hospitals' departments. Based on the results of the present study, it was concluded that, half percent of nurses in study group has bachelor degree compared to near three quarters of nurses in control group. In addition, there were highly statistically significant difference related to mean scores for Caring Behavior Assessment (CBA) as rated by nurses in posttest (3.5 to 4.55 ) than pretest (1.4750 to 2.075). Lastly, there were a statistical significance difference between educational qualifications of nurses andan Supportivelprotectivelcorrective environment subscale with mean score for master 57.000 .

\section{Recommendation}

Based on the previous findings, it was recommended that:

1. Developing a more comprehensive and short quantitative tool to measure caring for future researches and Patient satisfaction surveys should become a regular outcome monitoring feature in all hospitals.

2. In-service training programs for nurses about caring behavior and its different areas, with special emphasis on communication are needed to improve their own behaviors in all aspects of the caring behaviors for all health care settings.

3. Motivating hospital authorities to recruit more nurses, then, the nurses would be able to have more care that is direct. Consequently, the amount and the quality of nurse-child communication and opportunities for patient education would increase, this in turn improve child's outcome.

\section{References}

[1]. Hockenberry M .J. Wilson, D .Wong's Nursing Care of Infants and Children. Mosby, MO, Louis; 2011.

[2]. Lochner KA, Cox CS. Prevalence of multiple chronic conditions among Medicare beneficiaries, United States, 2010. Prev Chronic Dis 2013;10:E61.

[3]. Andereson G. Chronic care: making the case for ongoing care. Princeton (NJ): Robert Wood Johnson Foundation; 2010. http://www.rwjf.org/content/dam/farm/reports/reports/2010/rwjf54583. Accessed September 1, 2014.

[4]. Van Cleave J, Gortmaker SL, Perrin JM. Dynamics of obesity and chronic health conditions among children and youth. JAMA 2010;303(7):623-30

[5]. Perrin JM, Bloom SR, Gortmaker SL. The increase of childhood chronic conditions in the United States. JAMA 2007;297(24):2755-9.

[6]. Santos MR, Bousso RS, Vendramim P, Baliza MF, Misko MD, Silva L. The practice of nurses caring for families of pediatric inpatients in light of Jean Watson.Rev Esc Enferm USP. 2014 Aug;48 Spec No:80-6

[7]. Watson, J. Nursing, human science and human care, a theory of nursing. Sudbury, MA: Jones and Bartlett Publish-ers, 1999.

[8]. Adereti. S, Ayobola. O, Elizabeth .O, Kikelomo .A.Paediatric Patients and Primary Care Givers' Perception of Nurse-Caring Behaviour in South Western Nigeria.International Journal of Caring Sciences May-August 2014 Vol 7 Issue 2

[9]. Watson, J. Caring science: Belonging before being as ethical cosmology. Nursing Science Quarterly, 2005; 18(4), 304-305. 
[10]. Vance, T. Caring and the professional practice of nursing. RN Journal. Available at http://www.rnjournal.com/journal_of_nursing/caring.htm .Retrieved December 30, 2012.

[11]. Boev, C.The relationship between nurses' perception of work environment and patient satisfaction in adult critical care. Journal of Nursing Scholarship, 2012; 44(4), 368-375.

[12]. Fawcett J. Watson's theory of human care. In Contemporary Nursing Knowledge an Analysis and Evaluation of Nursing Models and Theories. (2nd ed., p.553-599). Philadelphia: PA. F.A.Davis Company, (2005).

[13]. Lukose A. Developing a practice model for Watson's theory of caring. Nursing ScienceQuarterly; 2011, 24: $27-30$

[14]. Watson J. Caring as the essence and science of nursing and health care. O Mu n dO d aSa d e Səo Paulo; 2009, 33: 143-149.

[15]. Watson J.Watson's theory of human carıng and subjectıve living experıences: caratıvefactors/cartas processes as a disciplinary guide to the professional nursing practice. TextoContextoEnferm, Florianopolis: 2007, 16: 129-135.

[16]. Michie S, Miles J, Weinman J. Patient-centeredness in chronicillness: what is it and does it matter? Patient EducCouns2003;51:197-206.

[17]. Rady. H.I. Profi le of patients admitted to pediatric intensive care unit, Cairo University Hospital: 1-year study,Ain-Shams Journal of Anesthesiology,2014; 07:500-503

[18]. Aslan, S., Ozer, N. Complementary treatments for emotional problems of patients hospitalized in intensive care unit. Anatolian Nursing and Health Science Journal, 2010; 13, 68-75.

[19]. Tracy, M.F., Chlan, L. Nonpharmacological Interventions to Manage Common Symptoms in Patients Receiving Mechanical Ventilation.Critical Care Nurse, 2011; 31, 19-28.

[20]. Cronin N., Harrison, B. Caring Behavior Assessment tool.In Watson (Ed,) assissing and measuring caring in nursing and health science (pp 77-90) New York springer;1988.

[21]. Wu, Y., Larrabee, J. H., \& Putman, H. P.Caring behaviors inventory: A reduction of the 42item instrument. Nursing Research, 2006; 55(1), 18-25.

[22]. Watson, J. Assessing and measuring caring in nursing and health science, New York Springer Publishing Company, (2002); 11-19

[23]. Mizuno, M., Ozawa, M., Evans, D.,Okada, A., Takeo, K., (2005): Caring Behaviors Perceived by Nurses in a Japanese Hospital, J Nurs Studies NCNJ. Vol.4, No.(1), p.p. 13- 19.

[24]. Suliman W A, Welmann E, Omer T and Thomas L, Joumal of Nursing Research 2009; 17(4), 293-300.

[25]. O'Connell E. and Landers M. The importance of critical care nurses' caringbehaviours as perceived by nurses and relatives, Intensive and Critical Care Nursing (2008) 24, 349-358.

[26]. Villanueva N. Experiences of critical care nurses' caring for unresponsive patients. J NeurosciNurs 1999;31(4):216-23.

[27]. Liu, J. E., Mok, E., \& Wong, T. Caring in nursing: Investigating the meaning of caring fromthe perspective of cancer patients in Beijing, China.Journal of Clinical Nursing, 2006; 75(2), 188-196

[28]. Azizi-Fini I, Mousavi MS, Mazroui-Sabdani A, Adib-Hajbaghery M. Correlation Between Nurses' Caring Behaviors and Patients' Satisfaction. Nurs Midwifery Stud. 2012:1(1):36-40. DOI: 10.5812/nms.7901

[29]. Poirier, P.,\&Sossong, A. Oncology patients" and nurses" perceptions of caring.

[30]. Youssef, H.,A., Mansour, M., A., Ayasreh, I.,R and Al- Mawajdeh, N., A., (2013): A Medical-Surgical Nurse's Perceptions of Caring Behaviors among Hospitals in TaifCity,Life Science Journal 2013;10(4)

\begin{tabular}{|c|c|c|c|c|c|}
\hline & & \multicolumn{2}{|c|}{ Study Group (No.=40) } & \multicolumn{2}{|c|}{ Control Group ( No.=30) } \\
\hline & & No. & $\%$ & No. & $\%$ \\
\hline \multicolumn{6}{|c|}{ Age: } \\
\hline & $19-29$ & 26 & 65 & 26 & 86.7 \\
\hline & $30-40$ & 14 & 35 & 4 & 13.3 \\
\hline \multicolumn{6}{|c|}{ Income: } \\
\hline$\bullet$ & Enough. & 26 & 65 & 21 & 70 \\
\hline & Not Enough. & 14 & 35 & 9 & 30 \\
\hline \multicolumn{6}{|c|}{ Experience: } \\
\hline$\bullet$ & Less than 1 year. & 4 & 10 & 3 & 10 \\
\hline$\bullet$ & From 1 to less than 5 years & 13 & 32.5 & 10 & 33.3 \\
\hline$\bullet$ & From 5 to 10 years. & 12 & 30 & 9 & 30 \\
\hline$\bullet$ & More than 10 years. & 11 & 27.5 & 8 & 26.7 \\
\hline
\end{tabular}

Table (1): Distribution of Socio-demographic characteristics of nurses

\section{Level of Education for Study Group}

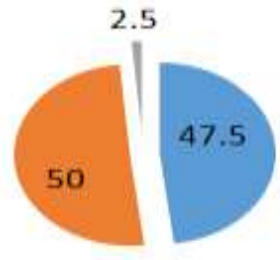

- Diploma

$$
\begin{aligned}
& \text { Bachelor } \\
& \text { Master } \\
& \text { Degree }
\end{aligned}
$$

\section{Level of Education for Control Group}

Figure (1): Level of Education for Study GroupFigure (2): Level of Education for Control Group 
Table (2): Distribution of children according to their age and diagnosis

\begin{tabular}{|l|l|l|}
\hline \multirow{2}{*}{ Age: } & No. $=\mathbf{4 0}$ & \% \\
\cline { 2 - 3 } & No. & \\
\hline $8-$ less than 10 years & & 55 \\
\hline More than 10 years. & 22 & 45 \\
\hline Diagnosis: & 18 & \\
\hline Pneumonias & & 37.5 \\
\hline Generalized hypotonic & 15 & 25 \\
\hline DKA & 10 & 15 \\
\hline Encephalopathy & 6 & 10 \\
\hline foreign body inhalation & 4 & 7.5 \\
\hline Heart failure & 3 & 5 \\
\hline
\end{tabular}

Table (3A): The mean differences of the seven CBA Itemsregarding Humanism/ Faith - hope / sensitivity and Helping/trust between study pre/post and control group

\begin{tabular}{|c|c|c|c|c|c|c|c|c|c|c|}
\hline \multirow[t]{3}{*}{ Variables } & \multicolumn{4}{|c|}{ Study Group (No, $=40)$} & \multirow{3}{*}{$t$-test } & \multirow{3}{*}{$\begin{array}{c}\text { P. } \\
\text { Value }\end{array}$} & \multirow{2}{*}{\multicolumn{2}{|c|}{$\begin{array}{c}\text { Control } \\
\text { Group }(\text { No. }=30)\end{array}$}} & \multirow{3}{*}{$t$ - test } & \multirow{3}{*}{$\begin{array}{c}\text { P. } \\
\text { value }\end{array}$} \\
\hline & \multicolumn{2}{|c|}{ Pretest } & \multicolumn{2}{|c|}{ Posttest } & & & & & & \\
\hline & M & So & M & SD & & & $M$ & So & & \\
\hline \multicolumn{11}{|l|}{ A. Humanism/Faith-Hope/ Sensitivity: } \\
\hline 1. Treat the child as an individual. & $1.5750^{\circ}$ & .71208 & 4.4250 & 1.12973 & 14.171 & .000 & 1.5667 & 72793 & 11.788 & .000 \\
\hline 2. Try to see things from the child point of view & 1.7250 & .78406 & 3.9250 & 1.02250 & 11.781 & 000 & 1.6667 & .75810 & 12.042 & .000 \\
\hline 3. Know what theyre doing & 2.0750 & .97106 & 4.2750 & 1.01242 & 8.943 & .000 & 1.9333 & .90719 & 11.673 & .000 \\
\hline 4. Reassure the child. & 1.4750 & 50574 & 4.4250 & 1.03497 & 17.198 & .000 & 1.5000 & .50855 & 16.155 & .000 \\
\hline 5. Make the chald feel somense is thete if I need them. & 1.0250 & 49029 & 4.2750 & 1.03744 & 13.390 & .000 & 1.6000 & 49827 & 17.588 & .000 \\
\hline 6. Encourage the child to believe in himself. & 1.4750 & .07889 & 4.4750 & .84694 & 16.432 & .000 & 1.4333 & .62606 & 12540 & .000 \\
\hline $\begin{array}{l}\text { 7. Point out positive things about the child and his } \\
\text { condition. }\end{array}$ & 1.6750 & .72986 & 4.3000 & .82275 & 13.933 & .000 & 1.7000 & 70221 & 13.260 & .000 \\
\hline 8. Praise the child efforts. & 20750 & 82858 & 4.3250 & 99711 & 10.981 & 000 & 2.0333 & .76489 & 14560 & .000 \\
\hline 9. Understand me. & 1.6750 & .69384 & 3.5000 & 1.26085 & 8.508 & 000 & 1.6667 & .71116 & 12.836 & .000 \\
\hline 10. Ask the child how be likes things done. & 1.8750 & 72280 & 3.8750 & 1.18078 & 9309 & 000 & 1.9000 & 71197 & 14.617 & 000 \\
\hline 11. Accegt the child the way be is & 1.7250 & .84694 & 4.2750 & 98677 & 13.471 & .000 & 1.7000 & .79438 & 11.721 & .000 \\
\hline 12 Be sensitive to the child feelings and moods. & 1.5750 & .59431 & 4.3250 & .79703 & 18.766 & 000 & 1.5333 & .57135 & 14.699 & .000 \\
\hline 13. Be kind and considerate. & 1.4750 & .59861 & 4.2250 & 1.02501 & 15.760 & .000 & 1.5000 & .62972 & $13: 047$ & .000 \\
\hline $\begin{array}{l}\text { 14. Keow when the child 'had enough" and act accordingly } \\
\text { (for example, limiting visitors) }\end{array}$ & 1.5750 & .67511 & 43250 & 1.04728 & 14.324 & 000 & 1.5667 & .67891 & 12.639 & .000 \\
\hline 15. Maintain a calm manver. & 1.7250 & .81610 & 4.1750 & .95736 & 11920 & .000 & 1.8333 & 83391 & 12.042 & .000 \\
\hline 16. Treat the child with repect. & 1.6250 & 58562 & 4.4500 & 71432 & 21.978 & 000 & 1.6333 & 55605 & 16.089 & .000 \\
\hline \multicolumn{11}{|l|}{ B. Helping/Trust; } \\
\hline 17. Really listen to the child when he taiks & 1,3250 & .57233 & 43250 & 82858 & 18.735 & .000 & 1.2667 & 52083 & 13.321 & .000 \\
\hline 18. Accept the child feelings without judging bem. & 1,7750 & 65974 & 4.0000 & 1.08604 & 12.309 & .000 & 1,7667 & 62606 & 15.456 & .000 \\
\hline 19. Come into the child room just to check on him. & 1.4250 & 59431 & 3.5000 & 1.24035 & 10.183 & .000 & 1,3607 & 55605 & 13.462 & .000 \\
\hline 20. Talk to the child about his life outside hospital. & 1.8250 & .71208 & 3.6750 & 1.20655 & 8.432 & .000 & 1.7667 & .67891 & 14.253 & .000 \\
\hline 21. Ask the child what be likes to be called. & 1.5750 & 63599 & 3.6250 & 1.05460 & 10.462 & .000 & 1.5667 & .62606 & 13,706 & .000 \\
\hline 22. Introduce themselves to the child. & 1.8250 & 59431 & 4.2750 & 87669 & 13.181 & .000 & 19333 & 58329 & 18.154 & .000 \\
\hline 23. Answer quickly when the child ofll for them. & 1.7500 & 66986 & 42250 & .86194 & 14.741 & .000 & 1.7667 & .67891 & 14.253 & 000 \\
\hline 24. Give the child their full attention when with him. & 1.7500 & .74248 & 4.2000 & .75786 & 15.319 & .000 & 1.6333 & .71840 & 12.453 & .000 \\
\hline 25. Visit the child if be moves to abother bospital unit. & 1.8500 & .62224 & 3.5500 & 1.21845 & 7,583 & .000 & 1.8667 & 57135 & 17.395 & .000 \\
\hline 26. Touch the child when he need it for comfort & 1.4250 & 39431 & 3.5000 & 1.32045 & 8.602 & .000 & 1.3667 & 55005 & 13.462 & .000 \\
\hline 27. Do what they say they will do. & 1.8250 & 71208 & 3.4000 & 1.31656 & 6.565 & .000 & 17667 & .67891 & 14.253 & .000 \\
\hline
\end{tabular}


Table (3B): The mean differences of the seven CBA Items regardingExpression of positive/negative feelingsTeaching/learning -Supportive/protective/corrective environment between study pre/post and control group

\begin{tabular}{|c|c|c|c|c|c|c|c|c|c|c|}
\hline \multirow[t]{3}{*}{ Variables } & \multicolumn{4}{|c|}{ Study Group (No. $=40$ ) } & \multirow{3}{*}{ t-test } & \multirow{3}{*}{$\begin{array}{c}\text { P. } \\
\text { Value }\end{array}$} & \multirow{2}{*}{\multicolumn{2}{|c|}{$\begin{array}{l}\text { Control } \\
\text { Group }(\text { No. }=30)\end{array}$}} & \multirow{3}{*}{ t- test } & \multirow{3}{*}{$\begin{array}{c}\mathrm{P} \text {. } \\
\text { Value }\end{array}$} \\
\hline & \multicolumn{2}{|c|}{ Protest } & \multicolumn{2}{|c|}{ Posttest } & & & & & & \\
\hline & $M$ & SD & M & SD & & & M & SD & & \\
\hline \multicolumn{11}{|l|}{ C. Expression of Positive Negative Feelings: } \\
\hline 28. Encourage the child to talk about bow he feeis. & 1.5750 & .63599 & 4.0000 & 1.17670 & 11.810 & .000 & 1.5667 & .62606 & 13.706 & .000 \\
\hline 29. Dont become upset when Im angry & 1.8250 & .59431 & 43750 & .77418 & 17.298 & .000 & 1.9333 & .58329 & 18.154 & .000 \\
\hline 30. Help the child understand his feetings. & 1.7500 & .66986 & 3.9250 & 94428 & 12.429 & .000 & 1.7667 & .67891 & 14.253 & .000 \\
\hline 31. Dont give up on the child when him difficult to get & 1.7500 & 74248 & 4.1750 & 84391 & 12.825 & .000 & 1,6333 & .71840 & 12.453 & .000 \\
\hline \multicolumn{11}{|l|}{ D. TeachinglLeaming: } \\
\hline $\begin{array}{l}\text { 32. Encourage the child to ask questions about his illiness } \\
\text { and treatmeat. }\end{array}$ & 1.8500 & .02224 & 4.2750 & $\$ 1610$ & 16.013 & .000 & 1.8667 & 57135 & 17.895 & .000 \\
\hline 33. Answe the child questions clearly. & 1.5750 & 71208 & 4.3750 & .74032 & 20.058 & .000 & 1.5667 & 72793 & 11.788 & .000 \\
\hline 34. Teach the child about his lliness & 1.7250 & .78406 & 4.1750 & 95776 & 13.982 & .000 & 1.6667 & .75810 & 12.042 & .000 \\
\hline 35. Ask the chald questions to be sure he understands. & 2.0750 & 97106 & 3.9000 & 87119 & 8.281 & .000 & 1.9333 & 90719 & 11.673 & .000 \\
\hline $\begin{array}{l}\text { 36. Ask the child what I want to know about his } \\
\text { bealth illness }\end{array}$ & 1.4750 & .50574 & 4.1000 & 92819 & 16.118 & .000 & 1.5000 & 50855 & 16.155 & 000 \\
\hline 37. Help thechild set realistic goals for my health. & 1.6250 & .49029 & 4.1250 & 93883 & 14.252 & .000 & 1.6000 & 49827 & 17.588 & .000 \\
\hline 38. Help thechild plan ways to meet those govls. & 1.4750 & 67889 & 4.1250 & 88252 & 16.326 & .000 & 1.4333 & .62606 & 12.540 & .000 \\
\hline 39. Help thechild plan for his discharge from hospital. & 1.6750 & .72086 & 39250 & 91672 & 12.631 & .000 & 1.7000 & .70221 & 13.260 & .000 \\
\hline \multicolumn{11}{|l|}{ E. Supportive/Protective' Corrective Environment: } \\
\hline 40. Tell the child what to expect during the day. & 2.0750 & 82858 & 39500 & 1.08486 & 9.693 & 000 & 2.0333 & 76489 & 14.560 & 000 \\
\hline 41. Understand when I need to be alone. & 1.6923 & 69410 & 4,0256 & 95936 & 13.149 & .000 & 1.6667 & .71116 & 12,836 & .000 \\
\hline $\begin{array}{l}\text { 42. Offer things (position changes, blankets, back rub, } \\
\text { tighting, etc.) to make the child more comfortable. }\end{array}$ & 1.8750 & .72280 & 4,1000 & 90014 & 11.074 & .000 & 19000 & .71197 & 14.617 & 000 \\
\hline 43. Leave the child room neat after working with him. & 1.7250 & .84694 & 4.4000 & 87119 & 12.929 & .000 & 1.7000 & 79438 & 11.721 & .000 \\
\hline 44. Exptain safety precautions to the child andhis family. & 1.5750 & 59431 & 4.4000 & 70892 & 19.199 & .000 & 1.5333 & 57135 & 14699 & .000 \\
\hline 45. Give the childpain medication when he needs it. & 1.4750 & 59861 & 4.2500 & 98058 & 16.719 & .000 & 15000 & 62972 & 13.047 & .000 \\
\hline 46. Encourage the child to do what be ean for himself. & 1.5750 & .67511 & 4.3250 & .61550 & 18.230 & .000 & 1.5667 & .67891 & 12.639 & .000 \\
\hline 47. Respect the child modesty as, keeping his covered. & 1.7250 & 81610 & 4.4000 & 70892 & 14.827 & .000 & 1.8333 & 83391 & 12.042 & .000 \\
\hline $\begin{array}{l}\text { 48. Check with the child before leaving the room to be sure } \\
\text { be has everything be needs within reach. }\end{array}$ & 1.6250 & 58562 & 4.2000 & .93918 & 16.126 & .000 & 1.6333 & .55605 & 16.089 & .000 \\
\hline 49. Consider the child spiritual needs. & 1.3250 & .57233 & 4.1750 & .90203 & 16.402 & .000 & 1.2667 & 32083 & 13.321 & .000 \\
\hline 50. Are gentle with the child. & 1.7750 & .65974 & 39250 & 91672 & 11.879 & .000 & 1.7667 & .62606 & 15.456 & .000 \\
\hline 51. Are cheerful. & 1.4250 & 59431 & 43750 & 80662 & 19.446 & .000 & 1.3667 & .55605 & 13,462 & .000 \\
\hline
\end{tabular}


Table (3C): The mean differences of the seven CBA Itemsregarding Human needs assistance -Existential/ phenomological/ spiritual forces between study pre/post and control group

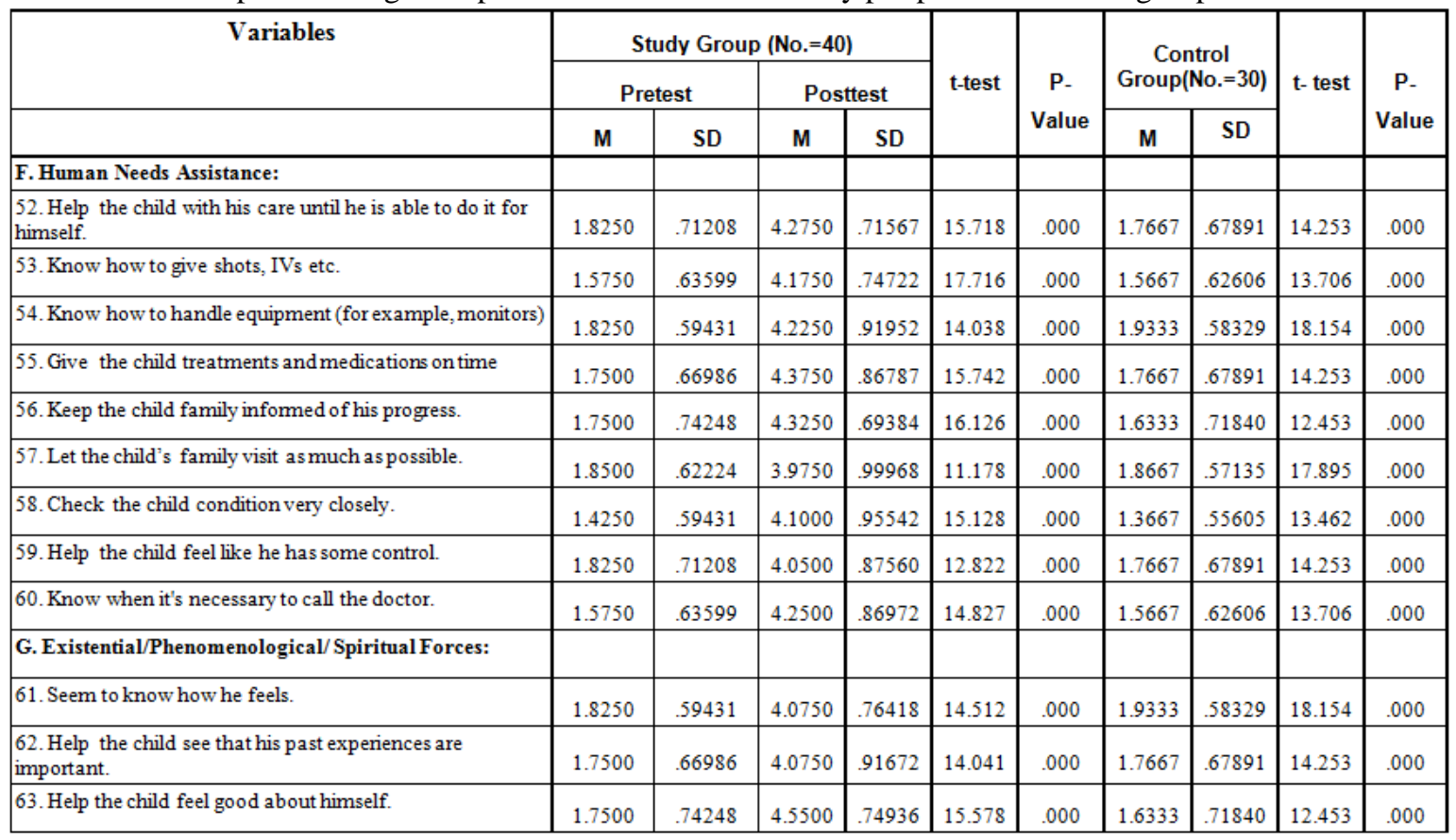

Table(4): Barriers of Nursing Staff to less interest of comfort behavior

\begin{tabular}{|l|l|l|l|}
\hline \multicolumn{2}{|c|}{} & \multicolumn{2}{l|}{ Total Nurses (No.=70) } \\
\cline { 3 - 4 } \multicolumn{2}{|c|}{} & No. & \% \\
\hline & Shortage of nursing staff & 32 & 45.7 \\
\hline & Large number of patients & 35 & 50 \\
\hline & Heavy workloads & 37 & 52.9 \\
\hline & Secretarial jobs for nurses & 15 & 21.4 \\
\hline & Emotional stress & 20 & 28.6 \\
\hline & Doing doctor order & 45 & 64.3 \\
\hline
\end{tabular}

Table (5): Relation between Level of Education of Nurses \& Their Perception toward CBA

\begin{tabular}{|c|c|c|c|c|c|}
\hline & \multicolumn{3}{|l|}{ Pretest } & \multirow[t]{2}{*}{$\mathbf{F}$} & \multirow[t]{2}{*}{$\mathbf{P}$} \\
\hline & Diploma & Bachelor & Master & & \\
\hline \multirow{3}{*}{$\begin{array}{l}\text { Humanism Ifaith-hopelsensitivityMean } \\
\text { +SD } \\
\text { N }\end{array}$} & 66.1579 & 68.5500 & 75.0000 & .559 & .576 \\
\hline & 12.17586 & 7.42311 & - & & \\
\hline & 19 & 20 & 1 & & \\
\hline \multirow{3}{*}{$\begin{array}{l}\text { Helping ItrustMean } \\
\text { +SD } \\
\mathrm{N}\end{array}$} & 41.8421 & 42.5000 & 46.0000 & .244 & .785 \\
\hline & 5.73743 & 6.51718 & & & \\
\hline & 19 & 20 & 1 & & \\
\hline \multirow{3}{*}{$\begin{array}{l}\text { Expression of positive } \backslash \text { negative feelingsMean } \\
\text { +SD } \\
\text { N }\end{array}$} & 16.1053 & 16.6500 & 20.0000 & 1.245 & .300 \\
\hline & 2.70585 & 2.30046 & - & & \\
\hline & 19 & 20 & 1 & & \\
\hline \multirow{3}{*}{$\begin{array}{l}\text { Teaching learningMean } \\
\text { +SD } \\
\mathrm{N}\end{array}$} & 33.3158 & 32.4500 & 38.0000 & .969 & .389 \\
\hline & 4.39763 & 3.84537 & - & & \\
\hline & 19 & 20 & 1 & & \\
\hline \multirow{3}{*}{$\begin{array}{l}\text { Supportivelprotectivel corrective environment } \\
\text { Mean } \\
\text { +SD } \\
\text { N }\end{array}$} & 52.3158 & 48.8500 & 57.0000 & 3.007 & $.062 *$ \\
\hline & 4.83106 & 5.38297 & - & & \\
\hline & 19 & 20 & 1 & & \\
\hline \multirow{3}{*}{$\begin{array}{l}\text { Human needs assistanceMean } \\
+\mathrm{SD} \\
\mathrm{N}\end{array}$} & 38.7895 & 36.7000 & 39.0000 & 1.258 & .296 \\
\hline & 3.89557 & 4.44972 & - & & \\
\hline & 19 & 20 & 1 & & \\
\hline \multirow{3}{*}{$\begin{array}{l}\text { Existentiallphenomenological lspiritual } \\
\text { forcesMean } \\
\text { +SD } \\
\mathrm{N}\end{array}$} & 12.6316 & 12.6500 & 15.0000 & .804 & .455 \\
\hline & 2.08728 & 1.56525 & - & & \\
\hline & 19 & 20 & 1 & & \\
\hline
\end{tabular}


Table (6): the Relation between Years of Experience of Nurses \& Their Perception toward CBA Subscale

\begin{tabular}{|c|c|c|c|c|c|c|}
\hline & \multicolumn{4}{|l|}{ Pretest } & \multirow[t]{2}{*}{$\mathbf{F}$} & \multirow[t]{2}{*}{$\mathbf{P}$} \\
\hline & less than year & $\begin{array}{ll}1 \text { to } & \text { less } \\
\text { than } 5 & \\
\end{array}$ & $\begin{array}{l}\text { from } 5 \text { to } \\
10\end{array}$ & more than 10 & & \\
\hline \multirow{3}{*}{$\begin{array}{l}\text { Humanism Ifaith-hopelsensitivityM } \\
+ \text { SD } \\
\mathrm{N}\end{array}$} & 68.500 & 66.538 & 66.916 & 69.181 & .162 & .921 \\
\hline & 6.454 & 14.65501 & 7.1281 & 7.1807 & & \\
\hline & 4 & 13 & 12 & 11 & & \\
\hline \multirow{3}{*}{$\begin{array}{l}\text { Helping ItrustM } \\
+ \text { SD } \\
\mathrm{N}\end{array}$} & 39.750 & 42.9231 & 41.833 & 42.909 & .328 & .805 \\
\hline & 7.1355 & 6.90967 & 4.9878 & 42.909 & & \\
\hline & 4 & 13 & 12 & 11 & & \\
\hline \multirow{3}{*}{$\begin{array}{l}\text { Expression of positivelnegative feelingsM } \\
+ \text { SD } \\
\mathrm{N}\end{array}$} & 18.000 & 15.7692 & 15.833 & 17.454 & 1.73 & .178 \\
\hline & 2.1602 & 3.11325 & 2.0375 & 2.0181 & & \\
\hline & 4 & 13 & 12 & 11 & & \\
\hline \multirow{3}{*}{$\begin{array}{l}\text { Teaching Vearning } \mathrm{M} \\
+ \text { +SD } \\
\mathrm{N}\end{array}$} & 32.000 & 32.3846 & 33.000 & 34.090 & .413 & .745 \\
\hline & 4.5460 & 4.85693 & 3.7172 & 3.7803 & & \\
\hline & 4 & 13 & 12 & 11 & & \\
\hline \multirow{3}{*}{$\begin{array}{l}\text { Supportivelprotectivelcorrective } M \\
\text { Environment+SD } \\
\mathrm{N}\end{array}$} & 49.750 & 49.9231 & 49.583 & 53.181 & 1.09 & .365 \\
\hline & 5.6199 & 6.19760 & 4.8328 & 4.7078 & & \\
\hline & 4 & 13 & 12 & 11 & & \\
\hline \multirow{3}{*}{$\begin{array}{l}\text { Human needs assistance } M \\
\text { +SD } \\
\mathrm{N}\end{array}$} & 35.250 & 37.1538 & 36.833 & 40.363 & 2.38 & $.086^{*}$ \\
\hline & 4.0311 & 5.39824 & 3.5376 & 2.0626 & & \\
\hline & 4 & 13 & 12 & 11 & & \\
\hline \multirow{3}{*}{$\begin{array}{l}\text { Existential } \backslash \text { phenomenological } \backslash \text { spiritual } \\
\text { forces } \\
\text { M } \\
\text { +SD } \\
\text { N }\end{array}$} & 12.750 & 12.0769 & 12.833 & 13.272 & .877 & .462 \\
\hline & 2.2173 & 2.39658 & 1.0298 & 1.6180 & & \\
\hline & 4 & 13 & 12 & 11 & & \\
\hline
\end{tabular}

